\title{
Hb Sallanches: A Rare Mutational Variant of Alpha Thalassemia with Codon 105 Involvement
}

\author{
Maria Zahid Ahmed ${ }^{1, *}$, Amber Younas ${ }^{1}$, Saba Shahid², Saima Munzir ${ }^{1,2}$, Munira Borhany ${ }^{1}$, \\ Tahir Sultan Shamsi ${ }^{1}$ \\ ${ }^{1}$ Department of Clinical Hematology, National Institute of Blood Disease \& Bone Marrow Transplantation, Karachi, Pakistan. \\ ${ }^{2}$ Department of Clinical Genetics \& Genomics, National Institute of Blood Disease \& Bone Marrow Transplantation, \\ Karachi, Pakistan.
}

\begin{abstract}
Thalassemia is the most prevalent disease in our part of the world. Due to its mode of inheritance, timely diagnosis and identification can help in eradicating the fatal and life threatening consequences of this disease. With the advent of new molecular and genetic testing, many novel and rare mutations have been diagnosed that have their own clinical implications. We hereby report a case of a 40 year old male with multiple comorbidities and significant family history of sibling death at early age. He was worked up and identified as a case Hb Sallanches which is a rare mutational variant of Alpha thalassemia with codon 105 involvement. This case report highlights the significance of timely diagnosis and identification of this disease in order to limit its fatal consequences on morbidity and mortality. This will assist in improving quality of life of such patients and will also help them to plan and save their future generations from this disease.
\end{abstract}

Keywords: Hb Sallanches, Codon 105, Haemolytic anemia, Thalassemia, Genetic, Mutation.

\section{INTRODUCTION}

The abnormal production of globin chains leads to disorders termed as thalassemia. This decrease or absence of synthesis of globin chain halts the production of normal hemoglobin which in turn leads to limited production of red cells and intramedullary early cell death [1]. It is broadly classified as alpha or beta thalassemia due to inappropriate synthesis or deletion of alpha or beta globin chains. Alpha thalassemia is majorly due to the removal of a gene on chromosome 16 and in other few cases it is due to single gene mutation. Beta thalassemia is mostly due to single gene mutation on chromosome 11 [2]. There are two alpha chains and two beta chains in a normal adult hemoglobin ( $\alpha 2 \beta 2)$ and a pair of alpha chains and gamma chains in hemoglobin at fetal age $(\alpha$ $2 \gamma 2)$. The defective production of alpha chains during fetal life leads to the formation of gamma chains tetramers $(\gamma 4)$ leading to $\mathrm{Hb}$ Bart disease. However, the similar deficiency of alpha chains in adults, leads to the formation of Beta chain tetramers which is termed as Hemoglobin $\mathrm{H}(\mathrm{Hb} \mathrm{H})$ disease. These tetramers have high affinity for oxygen hence decreased capacity for transporting oxygen to the tissues. As a result of this, inclusion bodies are produced and this also leads to some amount of hemolysis [3]. Alpha thalassemia has more complex genetics as compared to beta thalassemia as each haploid genome makes $2 \alpha$-globin chains. The first group of Alpha thalassemia is $\alpha 0$ in which both the alpha genes are absent, then there are $\alpha+$ thalassemia in which one of the alpha gene is damaged further leading to deletion and non-deletion

*Address correspondence to this author at the Department of Clinical Hematology, National Institute of Blood Disease \& Bone Marrow Transplantation, Karachi, Pakistan. E-mail: mariazahid_90@yahoo.com kinds [4]. In South East Asia, $-\alpha^{3.7}$ and $-\alpha^{4.2}$ are the most frequently encountered single genes deleted in alpha thalassemia and amongst the two gene deletions in cis like ${ }^{-}$ SEA, - FIL, - -THAI are common. In the Mediterranean area, -MED and $-\alpha^{(20.5)}$ deletions of two genes are frequently seen [5]. In Pakistan, most common gene deletion is $-\alpha^{3.7}$ with a prevalence of about $8.3 \%$ [6]. We hereby report a patient who was identified with a rare variant of Alpha thalassemia, $\mathrm{Hb} \mathrm{H}$ disease due to $\mathrm{Hb}$-Sallanches which is produced by mutation on $\mathrm{HbA} 2$ gene involving a single base substitution at codon 105 of exon 3.

\section{CASE REPORT}

A 40 years old male presented to us with complaints of generalized weakness, abdominal distention and shortness of breath on exertion (NYHA GRADE 2). He had history of recurrent episodes of jaundice not associated with any drug or anything specific that the patient could relate to and he was not worked up for it in the past. Past history was significant for gouty arthritis for which he was on pain killers and a history of PRBC transfusion since the past 15 years with a frequency of once or twice/ month. He was a product of consanguineous marriage. Family history revealed death of 3 siblings at ages of 10,15 and 19 years respectively with similar complaints but they had never been diagnosed. On examination, he had pallor and abdominal dis-tention, tenderness in the right hypochondrium and spleen was palpable 6 fingers below the left costal margin. Rest of the general and systemic examination was unremarkable.

He was referred to National Institute of Blood Disease \& 
Bone Marrow Transplantation (NIBD) for the evaluation of anemia and splenomegaly. His complete blood count (CBC) revealed $\mathrm{Hb}$ of $9.2 \mathrm{~g} / \mathrm{dl}$ with an MCV of 98 , TLC $9.2 \times 10^{9} / \mathrm{L}$ and a Platelet count of $197 \times 10^{9} / \mathrm{L}$. Peripheral smear revealed a population of normochromic, normocytic, hypochromic, microcytic (dimorphic blood picture) with tear drop cells, microspherocytes, polychromatic cells and platelet anisocytosis. Reticulocyte count was $283 \times 10^{9} / \mathrm{L}$ with Uric Acid of $6.8 \mathrm{mg} / \mathrm{dL}$ and LDH of $389 \mathrm{U} / \mathrm{L}$. Biochemical studies, liver function tests, direct antiglobulin test and autoimmune profile were negative, viral serology was non-reactive. Ultrasound abdomen revealed cholilithiasis with hepatosplenomegaly and normal portal vein diameter.

Patient provided a report of $\mathrm{Hb}$ electrophoresis done from another laboratory, which showed $\mathrm{Hb}-\mathrm{A} 93.4 \%$ and $\mathrm{HbA} 2$ $6.6 \%$. Since the patient had received recent blood transfusions, we were unable to repeat this test. DNA mutation analysis for beta thalassaemia was performed in which 25 common mutations prevailing in Pakistani population were checked. It revealed no mutation. Alpha deletions for 3.7 and 4.2 were checked but were not detected. Bone Marrow aspirate and trephine were done to rule out Myelodysplastic Syndrome and it revealed erythroid hyperplasia with preserved myeloid series and megakaryopoises consistent with haemolytic anemia. Cytogenetics was found to be normal. Heat stability test revealed a weak precipitation at $500 \mathrm{C}$ at 60,120 and 180 minutes. We proceeded with our case by running inherited disease panel on Next Generation Sequencing in which 4813 genes were screened covering around 10,000 inherited disorders. It revealed a mutation on $\mathrm{HbA} 2$ gene with nucleotide change of c.314G $>$ A, a TGC $\rightarrow$ TAC single base substitution at codon 105 of exon 3, changing the cysteine residue to tyrosine that corresponds to $\mathrm{Hb}$ Sallanches, a rare variant of the alpha thalassemia. The patient did not have any normal sequence, making him a homozygote for $\mathrm{Hb}$-Sallanches. In homozygous state it behaves like $\mathrm{Hb} \mathrm{H}$ disease of intermediate severity.

The patient was put on supportive symptomatic care with blood transfusions and hematinics were started. Due to the increased and frequent requirement of blood transfusion, vaccinations followed by splenectomy were planned. Laparoscopic Cholecystectomy was planned for symptomatic gallstones and pain killers were continued for his arthritis. Genetic counseling and screening of his kids was planned. The patient is on our regular hematological follow up.

\section{DISCUSSION}

$\mathrm{Hb} \mathrm{H}$ is a relatively unstable hemoglobin in which oxidation can lead to precipitation of Hemoglobin within the cell. This in turn leads to production of ineffective red blood cells and also to intramedullary hemolysis. More commonly, the cell membrane attaches these precipitates causing the cell membrane to be unstable and this in turn leads to cell rupture and cell death [7]. Hence, the most common cause of anemia in $\mathrm{Hb} \mathrm{H}$ disease is cell destruction. However, ineffective erythropoiesis also contributes to it [8]. $\mathrm{Hb} \mathrm{H}$ disease is divided into deletional or non deletional variants, in which the non deletional types are considered to be more severe [9]. Non deletion $\mathrm{Hb} \mathrm{H}$ subtypes are those in which one of the haploid genome has deletion of both the $\alpha$-globin chain plus the other genome has either a point mutation or deletion of either $\alpha 1$ or $\alpha 2$ globin chain. Clinically these patients have a higher degree of anemia, marked hepatosplenomegaly and the need of blood transfusion is more frequent. When each of the chromosome 16 has a non deletional $\alpha$ globin chain which is either homozygous or compound heterozygous, a variant similar to $\mathrm{Hb} \mathrm{H}$ disease is produced. This group comprises those with codon mutations including (ATG>ACG), Hb Sallanches (codon $105 \mathrm{TGC}>\mathrm{TAC}$ or $\mathrm{Cys} \rightarrow \mathrm{Tyr}$ ), or polyadenylation one gene mutation (AATAAA>AATAAG) [10]. Hb Sallanches results from a rare mutation, aSal, in which cysteine is replaced by tyrosine (TGC $\rightarrow$ TAC) at codon 105 of alpha globin chain. The first case of $\mathrm{Hb}$ Sallanches was reported in 1995 in a French family, and in Pakistan it was first reported in the year 2000 where 3 members of the same family were found to affected [11-13]. All the patients identified with this mutation have been found to be homozygous showing that the heterozygous carriers are usually asymptomatic and hence leading to difficulty in their identification. In homozygous state it behaves as thalassemia intermedia. This case report guides towards the diagnostic and prognostic significance of rare variants of alpha thalassemia with rare gene mutations. This will aid in improving the morbidities associated with these variants and also would help in limiting its spread by educating the carriers.

\section{CONCLUSION}

Rarer variants of alpha thalassemia have their own prognostic significance and timely identifying these mutations and managing these patients can limit the manifestations of side effects. In addition, identifying the carriers and appropriate genetic counseling can also further help in limiting the disease burden in our society.

\section{CONFLICT OF INTEREST}

Declared none.

\section{ACKNOWLEDGEMENTS}

We acknowledge all our fellow colleagues.

\section{REFERENCES}

[1] Harewood J, Bhimji SS. Alpha thalassemia (Hemoglobin H Disease). Abstract. Treasure Island (FL): StatPearls Publishing 2017; Available at : https://europepmc.org/abstract $/ \mathrm{med} / 28722856$ 
[2] Sabath DE. Molecular diagnosis of thalassemias and hemoglobinopathies: An ACLPS critical review. Am J Clin Pathol 2017; 148(1): 6-15. DOI: 10.1093/ajcp/aqx047

[3] Piel FB, Weatherall DJ. The $\alpha$-thalassemias. New Eng J Med 2014; 371(20): 1908-16. DOI: 10.1056/NEJMra1404415

[4] Weatherall DJ. The thalassemias. Methods Hematol 2001; 8 DOI: $10.1006 /$ rwgn.2001.1286

[5] Shahid S, Zahid D, Hassan J, Ansari S, Shamsi T. Alpha thalassemia deletions found in suspected cases of beta thalassemia major in Pakistani population. Pak J Med Sci 2017; 33(2): 411. DOI: 10.12669/pjms.332.11834

[6] Khan SN, Hasan F, Sollaino C, Perseu L, Riazuddin S. Molecular Characterization of $\alpha$-Thalassemia in Pakistan. Hemoglobin 2003; 27(3): 161-6. DOI: 10.1081/HEM-120023379

[7] Wasi P, Na-Nakorn S, SN P. Alpha - Thalassaemias. Clin Haematol 1974; 3(2): 383-410.

[8] Pootrakul P, Sirankapracha P, Hemsorach S, et al. A correlation of erythrokinetics, ineffective erythropoiesis, and erythroid precursor apoptosis in Thai patients with thalassemia. Blood 2000; 96(7): 2606-12.
[9] Kanavakis E, Papassotiriou I, Karagiorga M, et al. Phenotypic and molecular diversity of haemoglobin $\mathrm{H}$ disease: A Greek experience. Br J Haematol 2000; 111(3): 915-23. DOI: $10.1111 / \mathrm{j} .1365-2141.2000 .02448 . x$

[10] Chui DH, Fucharoen S, Chan V. Hemoglobin H disease: Not necessarily a benign disorder. Blood 2003; 101(3): 791-800. DOI: 10.1182/blood-2002-07-1975

[11] Morlé F, Francina A, Ducrocq R, et al. A new $\alpha$ chain variant $\mathrm{Hb}$ Sallanches [ $\alpha 2104$ (G11) Cys $\rightarrow$ Tyr] associated with $\mathrm{HbH}$ disease in one homozygous patient. Br J Haematol 1995; 91(3): 608-11. DOI: 10.1111/j.1365-2141.1995.tb05355.x

[12] Khan S, Butt F, Riazuddin S, Galanello R. Hb Sallanches [ $\alpha$ 104 (G11) Cys $\rightarrow$ Tyr]: A rare $\alpha 2$-globin chain variant found in the homozygous state in three members of a Pakistani family. Hemoglobin 2000; 24(1): 31-5. DOI: $10.3109 / 03630260009002271$

[13] Waye J, Walker L, Chui D, Lafferty J, Kirby M. Homozygous $\mathrm{Hb}$ Sallanches $[\alpha 104$ (G11) Cys $\rightarrow$ Tyr] in a Pakistani child with $\mathrm{Hb} \mathrm{H}$ disease. Hemoglobin 2000; 24(4): 355-7.

DOI: $10.3109 / 03630260008993145$ 